\title{
Effect of tobacco outlet density on quit attempts in Korea: a multi-level analysis of the 2015 Korean Community Health Survey
}

\author{
Jaehyung Kong ${ }^{1}$, Sung-il Cho² \\ ${ }^{1}$ National Tobacco Control Centre, Korea Health Promotion Institute, Seoul, Korea; ${ }^{2}$ Department of Public Health Sciences, Graduate School of \\ Public Health and Institute of Health and Environment, Seoul National University, Seoul, Korea
}

OBJECTIVES: This study aimed to examine whether the regional density of tobacco outlets in Korea was associated with the likelihood of attempting to quit among smokers

METHODS: This study was designed as a secondary data analysis of a cross-sectional study. Data from the 2015 Korean Community Health Survey and tobacco outlet registrations in 17 metropolitan cities and provinces with 254 communities in Korea were used for the analysis. In total, 41,013 current smokers ( $\geq 19$ years of age) were included. Multi-level logistic regression analysis was conducted to investigate regional differences associated with smokers' attempts to quit and to evaluate the effects of individual and regional characteristics on quit attempts.

RESULTS: Higher tobacco outlet density was associated with lower odds of attempting to quit. Smokers who resided in districts with the highest tobacco outlet density were $18 \%$ less likely to attempt quitting (odds ratio, $0.82 ; 95 \%$ confidence interval, 0.70 to 0.98 ) than smokers who resided in the regions with the lowest tobacco outlet density (intraclass correlation coefficient, 0.030 ).

CONCLUSIONS: This study showed that quit attempts were related to community-level factors, such as tobacco outlet density, as well as other individual factors. These findings support the implementation of national policies restricting the number of tobacco outlets within communities or zones and limiting tobacco marketing in tobacco outlets.

KEY WORDS: Tobacco, Tobacco product, Tobacco industry, Smoking cessation, Multilevel analysis

\section{INTRODUCTION}

Over 7 million people die worldwide due to smoking every year [1]. In Korea, the smoking prevalence among males is reported to be $38.1 \%$ [2]. With nearly four of every 10 males smoking, the socioeconomic costs associated with smoking-related diseases are

\section{Correspondence: Sung-il Cho}

Department of Public Health Sciences, Graduate School of Public Health and Institute of Health and Environment, Seoul National University, 1 Gwanak-ro, Gwanak-gu, Seoul 08826, Korea

E-mail: persontime@hotmail.com

Received: Feb 24, 2021 / Accepted: Aug 3, 2021 / Published: Aug 3, 2021

This article is available from: https://e-epih.org/

(c) This is an open-access article distributed under the terms of the Creative Commons Attribution License (https://creativecommons.org/licenses/by/4.0/), which permits unrestricted use, distribution, and reproduction in any medium, provided the original work is properly cited.

(C) 2021, Korean Society of Epidemiology estimated to be US\$6.1 billion [3].

The determinants of smoking and quitting smoking include individual factors and socioeconomic status. However, environmental factors can promote smoking and hinder smoking cessation [4]. The presence of tobacco outlets is an environmental factor that increases tobacco availability. These outlets are a key location for tobacco marketing, where individuals can access and purchase tobacco. In Korea, tobacco retailers sell tobacco products alongside other goods and services. While tobacco cannot be marketed through traditional media such as television, radio, and the Internet, tobacco marketing in tobacco outlets is legally permitted. Anyone may freely enter tobacco outlets, where they are exposed to tobacco advertisements. Despite these risks, tobacco outlets have not been recognized in tobacco control policies as an important factor associated with smoking and smoking cessation. To prevent smoking and create an environment that encourages smoking cessation, it is necessary to consider the effects of tobac- 
co outlets on smokers.

Numerous studies have reported the effects of tobacco outlets on smoking and smoking behaviour. Greater access to tobacco outlets facilitates purchases of tobacco because of the physical proximity to tobacco products and consumers' increased exposure to tobacco marketing through displays, advertisements, and sales promotions. Tobacco availability increases receptivity to smoking, thereby promoting the frequency of smoking and tobacco purchasing behaviours [5]. Regions with high tobacco retail density can cause price competition among products, which leads to reduced tobacco prices, further encouraging tobacco purchases [6]. Adults who reside in regions with high tobacco outlet densities are reportedly more likely to start smoking than those who live in regions with lower tobacco outlet densities [7]. Moreover, tobacco outlet density hinders the likelihood of successfully quitting smoking. Individuals living in regions with high concentrations of tobacco retailers exhibit low self-efficacy related to smoking, are less likely to consider smoking cessation [8], and are less likely to attempt smoking cessation (odds ratio [OR], 0.54) [9]. Daily smokers have been reported to reside in regions with high tobacco outlet densities and are known to make fewer attempts to quit, compared to those who rarely smoke [10]. Individuals with greater access to tobacco retailers who attempt to quit are reportedly less likely to successfully cease smoking [11-14]. Furthermore, tobacco outlet density within a residential area is associated with increased smoking frequency [15], and individuals who reside closer to tobacco retailers have higher levels of tobacco consumption [16].

Based on these known facts, this study aimed to investigate whether the environment related to tobacco retailers impacts adult smokers' attempts to quit smoking, for the first time in Korea, using nationwide data on tobacco retailers and current smokers. Based on these results, suggestions are made for the improvement of Korea's tobacco retailer control policies.

\section{MATERIALS AND METHODS}

\section{Data source and subjects}

In this study, data were collected from 254 communities on adult smokers, the number of tobacco outlets, population, area size, and financial independence rates. Adult smokers' data (i.e., demographic characteristics and smoking behaviours) were obtained from the 2015 Korean Community Health Survey (KCHS). Data from the Ministry of the Interior and Safety (2015) regarding the occupational information of licensed businesses were used to identify all types (e.g., convenience stores, grocery stores, stationary stores, tobacconist shop, etc.) of currently registered tobacco retailers. Data on the community population and area size were gathered from the Ministry of the Interior and Safety (2016) records of local governments and demographics. Data on the financial independence rate, which was defined as the ratio of the local government's generated revenue (independent income) to the local government's total revenue, were collected by Local Fi- nance 365 , a public finance data system operated by the Ministry of the Interior and Safety, in 2015. Since 2008, the Korea Disease Control and Prevention Agency (formerly Korea Centers for Disease Control and Prevention) has conducted the annual KCHS among male and female $\geq 19$ years of age in 17 metropolitan cities and provinces with 254 communities. A sample of 900 individuals per community was selected by multi-level probability sampling, with respect to the community classification and type of residence [17]. Of 228,558 respondents in 2015, 41,678 were identified as current smokers. Of the current smokers, 665 participants were excluded because of responses of "do not know" or refusal to respond to all survey questions. The remaining 41,013 participants were included in this study.

\section{Variables}

This study aimed to investigate current smokers' experiences with smoking cessation. A current smoker was defined as an individual who had smoked at least 5 packs of cigarettes (equivalent to 100 cigarettes) in their lifetime and currently smoked, either occasionally or on a daily basis. Participants were considered to have attempted quitting if they responded that they "tried to quit smoking in the past 1 year" to the question, "Have you stopped smoking for at least 1 day ( 24 hours) in an attempt to quit smoking permanently?" Several individual-level and community-level variables were analysed to assess their effects on attempts to quit.

\section{Individual-level measures}

Individual status variables consisted of demographic characteristics and smoking behaviours. The demographic variables included age, education level, marital status, occupation, and household income. The smoking behaviour variables included smoking frequency, number of cigarettes consumed per day, presence or absence of a health professional's recommendation to quit smoking, smoking cessation education experience, and anti-smoking campaign exposure.

\section{Community-level measures}

The community-level variables included the financial independence rate, community classification, area size, and tobacco outlet density. The 254 communities were divided into quartiles based on their financial independence rates. A higher financial independence rate was considered indicative of a greater ability of a local government to autonomously manage its finances. In this study, metropolitan cities $(\mathrm{gu})$ were classified as metropolis, small-medium cities (si) as city, and counties (gun) as rural. Communities were categorized into quartiles based on area size $\left(\mathrm{km}^{2}\right)$. Lastly, the tobacco outlet density was defined as the number of tobacco outlets per 1,000 residents in a community.

\section{Statistical analysis}

All obtained data were analysed using Stata version 15.0 (StataCorp., College Station, TX, USA). Descriptive statistics were used to analyse general characteristics according to the variables of in- 
dividual status and community status. Using MLwiN 2.36, multilevel logistic regression analyses were conducted to investigate the association between the community environment and current smokers' attempts to quit.

The formula used for the analysis was as follows:

$$
\log \left(\frac{p_{i j}}{1-p_{i j}}\right)=\gamma_{00}+\gamma_{01} z_{j}+\gamma_{10} x_{i j}+\delta_{0 j}, \quad \delta_{0 j} \sim N\left(0, \sigma_{\delta}^{2}\right)
$$

Multi-level logistic regression analysis was performed using a history of quit attempts as the dependent variable. For the multilevel analyses, we applied a random-intercept model. Three models were used in this study. The basic model (model 1) included only intercepts to identify significant differences in quit attempts between communities, the level 1 model (model 2) included only individual variables, and the level 2 model (model 3) included both individual and community variables. Intraclass correlation coefficients (ICCs) were calculated for each model to determine how much of the distribution was accounted for by communitylevel variables.

\section{Ethics statement}

The study protocol was approved by the Institutional Review Board (IRB) of Seoul National University (IRB No. E1802/003006).

\section{RESULTS}

\section{General characteristics of the study subjects}

Of the 41,013 study participants, $91.0 \%$ were males and $9.0 \%$ were females. Most participants were 40-49 years of age (25.2\%), followed by $50-59$ years of age (22.3\%), 30-39 years of age (19.5\%), $60-69$ years of age $(12.6 \%), 19-29$ years of age (11.4\%), and $\geq 70$ years of age (9.0\%). Participants' education levels varied; a highschool education was the most common level (38.2\%), followed by a college or university program $(36.0 \%)$, middle school or below $(23.2 \%)$, and graduate school or above (2.6\%). Most participants $(65.9 \%)$ had a spouse, while $34.1 \%$ did not. Most participants were blue-collar workers (58.9\%), followed by white-collar workers $(21.6 \%)$, unemployed (13.7\%), and others (5.8\%). The monthly household income of $<2.00$ million Korean won (KRW; 64.2\%), followed by 2.00-3.99 million KRW (32.5\%), and $\geq 4.00$ million KRW (3.3\%). Of current smokers, $91.0 \%$ smoked every day and $9.0 \%$ smoked some days; $54.8 \%$ smoked at least 11 cigarettes per day and $45.2 \%$ smoked 10 cigarettes or fewer per day. Nearly one-third (32.7\%) of current smokers had attempted to quit smoking within the past year (Table 1).

\section{Community characteristics}

The community-level variables, including financial independence rate, area size, and tobacco outlet density, are summarised in Table 2. Among the 254 communities throughout Korea, the mean financial independence rate was $30.2 \%$ (range, 9.9 to 64.5 ). The
Table 1. General characteristics of the study subjects

\begin{tabular}{|c|c|}
\hline Characteristics & n (\%) \\
\hline \multicolumn{2}{|l|}{ Current smoker $(n=41,013)$} \\
\hline \multicolumn{2}{|l|}{ Demographic status } \\
\hline \multicolumn{2}{|l|}{ Sex } \\
\hline Male & $37,313(91.0)$ \\
\hline Female & $3,700(9.0)$ \\
\hline \multicolumn{2}{|l|}{ Age (yr) } \\
\hline $19-29$ & $4,653(11.4)$ \\
\hline $30-39$ & $7,999(19.5)$ \\
\hline $40-49$ & $10,346(25.2)$ \\
\hline $50-59$ & $9,145(22.3)$ \\
\hline $60-69$ & $5,190(12.6)$ \\
\hline$\geq 70$ & $3,680(9.0)$ \\
\hline \multicolumn{2}{|l|}{ Education } \\
\hline Middle school or less & $9,503(23.2)$ \\
\hline High school & $15,682(38.2)$ \\
\hline College/university & $14,783(36.0)$ \\
\hline Graduate school or more & $1,045(2.6)$ \\
\hline \multicolumn{2}{|l|}{ Spouse } \\
\hline No & $13,995(34.1)$ \\
\hline Yes & $27,018(65.9)$ \\
\hline \multicolumn{2}{|l|}{ Occupation } \\
\hline Unemployed & $5,615(13.7)$ \\
\hline Blue-collar worker & $24,173(58.9)$ \\
\hline White-collar worker & $8,853(21.6)$ \\
\hline Other & $2,372(5.8)$ \\
\hline \multicolumn{2}{|c|}{ Household income ( $10^{4}$ Korean won) } \\
\hline$<200$ & $26,337(64.2)$ \\
\hline $200-399$ & $13,344(32.5)$ \\
\hline$\geq 400$ & $1,332(3.3)$ \\
\hline \multicolumn{2}{|l|}{ Smoking status } \\
\hline \multicolumn{2}{|l|}{ Smoking frequency } \\
\hline Occasional & $3,696(9.0)$ \\
\hline Daily & $37,317(91.0)$ \\
\hline \multicolumn{2}{|l|}{ Quit attempt } \\
\hline No & $27,580(67.3)$ \\
\hline Yes & $13,433(32.7)$ \\
\hline \multicolumn{2}{|l|}{ No. of cigarettes per day } \\
\hline$\leq 10$ & $18,544(45.2)$ \\
\hline$\geq 11$ & $22,469(54.8)$ \\
\hline \multicolumn{2}{|c|}{ Experience of smoking cessation education } \\
\hline No & $36,885(89.9)$ \\
\hline Yes & $4,128(10.1)$ \\
\hline \multicolumn{2}{|c|}{ Recommendation from a health professional to quit smoking } \\
\hline No & $28,073(68.5)$ \\
\hline Yes & $12,940(31.5)$ \\
\hline \multicolumn{2}{|c|}{ Exposure to anti-smoking campaigns } \\
\hline No & $4,722(11.5)$ \\
\hline Yes & $36,291(88.5)$ \\
\hline
\end{tabular}

mean regional area size was $395.0 \mathrm{~km}^{2}$ (range, 2.8 to $1,819.8$ ), and the mean tobacco outlet density was 3.9 stores per 1,000 residents (range, 1.3 to 15.5) (Figure 1 and Table 2). 
Table 2. Descriptive statistics for community-level variables

\begin{tabular}{lrrrr}
\hline Variables & Mean & $\begin{array}{c}\text { Standard } \\
\text { deviation }\end{array}$ & Minimum Maximum \\
\hline $\begin{array}{l}\text { Financial independence } \\
\text { rate (\%) }\end{array}$ & 30.2 & 13.3 & 9.9 & 64.5 \\
Area size $\left(\mathrm{km}^{2}\right)$ & 395.0 & 369.2 & 2.8 & $1,819.8$ \\
Tobacco outlet density (n) & 3.9 & 1.9 & 1.3 & 15.5 \\
$\quad$ Population & $202,871.4$ & $161,939.8$ & $10,153.0$ & $660,302.0$ \\
Tobacco outlets & 607.9 & 387.1 & 70.0 & $2,085.0$ \\
\hline
\end{tabular}
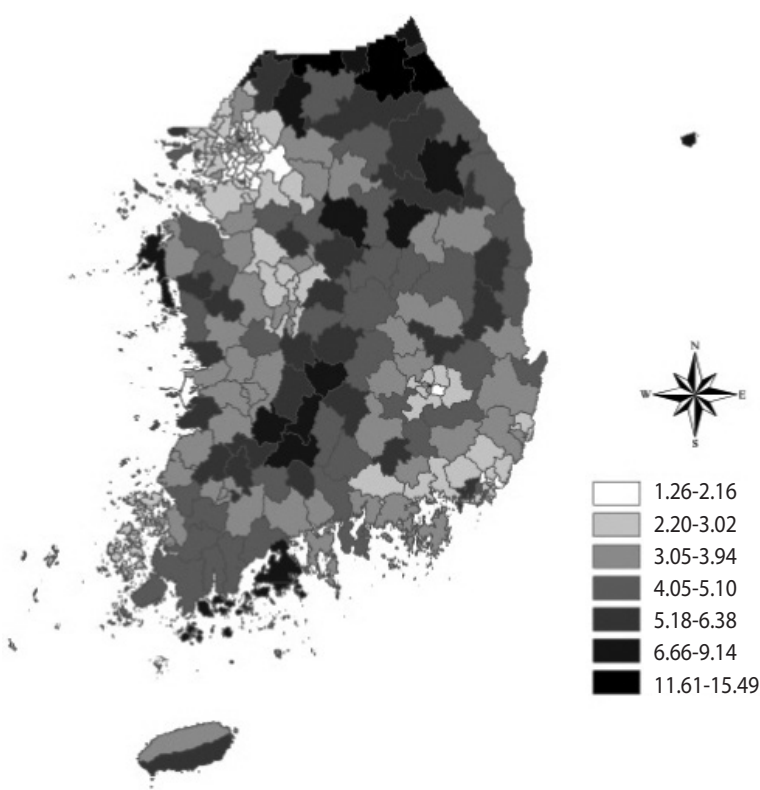

Figure 1. Distribution of tobacco outlet density (per 1,000 persons) across 254 communities in Korea.

\section{Effect of tobacco outlet density on quit attempts}

Multi-level logistic regression analysis was performed to investigate regional differences associated with smokers' attempts to quit (i.e., quit attempts), and to evaluate the effects of individual and regional characteristics on these quit attempts. Model 1 was a null model used to investigate the ICC, which indicated how much variation in smokers' attempts to quit existed between community-level units. Model 2 included individual variables and was therefore used to identify the individual factors that affected quit attempts. In addition to the individual-level characteristics included in model 2, several community-level variables (e.g., financial independence rate, community classification, area size, and tobacco outlet density) were included in model 3. Model 3 was used to investigate whether community-level variables affected individual smokers' attempts to quit.

The multi-level logistic regression results are summarised in Table 3. Regional differences were found to have statistically significant effects on quit attempts, demonstrating the presence of a local environment effect on smoking cessation. Several individu-
Table 3. Multi-level analysis result of factors associated with smokers' quit attempts

\begin{tabular}{lll}
\hline & \multicolumn{2}{c}{ Smokers' quit attempts } \\
\cline { 2 - 3 } Variables & Model 2 & Model 3
\end{tabular}

Fixed effects

Individual-level

Sex

Male

Female

Age (yr)

19-29

30-39

40-49

50-59

60-69

$\geq 70$

$\begin{array}{ll}1.00 \text { (reference) } & 1.00 \text { (reference) } \\ 0.81(0.74,0.88)^{* * * *} & 0.81(0.74,0.88)^{* * *} \\ & \\ 1.00 \text { (reference) } & 1.00 \text { (reference) } \\ 0.82(0.76,0.90)^{* * * *} & 0.83(0.76,0.91)^{* * *} \\ 0.69(0.63,0.75)^{* * * *} & 0.69(0.63,0.76)^{* * *} \\ 0.65(0.59,0.71)^{* * *} & 0.65(0.59,0.72)^{* * *} \\ 0.63(0.56,0.71)^{* * *} & 0.64(0.57,0.71)^{* * *} \\ 0.47(0.41,0.54)^{* * *} & 0.48(0.42,0.55)^{* * *}\end{array}$

Education

Middle school or less $\quad 1.00$ (reference) $\quad 1.00$ (reference)

High school $\quad 1.10(1.02,1.18)^{* *} \quad 1.10(1.02,1.18)^{* *}$

College/university $\quad 1.18(1.09,1.28)^{* * *} \quad 1.18(1.09,1.29)^{* * *}$

Graduate school or more $1.33(1.13,1.55)^{* * *} 1.32(1.12,1.53)^{* *}$

Spouse

No $\quad 1.00$ (reference) 1.00 (reference)

Yes $\quad 1.13(1.07,1.19)^{* * *} 1.13(1.08,1.19)^{* * *}$

Occupation

$\begin{array}{lll}\text { Unemployed } & 1.00 \text { (reference) } & 1.00 \text { (reference) } \\ \text { Blue-collar } & 1.14(1.06,1.24)^{* *} & 1.15(1.06,1.25)^{* *} \\ \text { White-collar } & 1.18(1.08,1.29)^{* *} & 1.18(1.08,1.30)^{* * *} \\ \text { Other } & 1.19(1.06,1.34)^{* *} & 1.20(1.06,1.36)^{* *}\end{array}$

Household income ( $10^{4}$ Korean won)

$<200 \quad 1.00$ (reference) 1.00 (reference)

200-399 $\quad 0.97(0.92,1.02) \quad 0.96(0.91,1.01)$

$\geq 400 \quad 1.10(0.97,1.24) \quad 1.09(0.97,1.24)$

Smoking frequency

Occasional $\quad 1.00$ (reference) $\quad 1.00$ (reference)

Daily $\quad 0.34(0.31,0.36)^{* * *} 0.34(0.31,0.37)^{* * *}$

No. of cigarettes per day

$\begin{array}{lll}\leq 10 & 1.00 \text { (reference) } & 1.00 \text { (reference) } \\ \geq 11 & 0.66(0.63,0.69)^{* * * *} & 0.66(0.63,0.69)^{* * * *}\end{array}$

Experience of smoking cessation education

$\begin{array}{lll}\text { No } & 1.00 \text { (reference) } & 1.00 \text { (reference) } \\ \text { Yes } & 1.55(1.44,1.67)^{* * *} & 1.56(1.45,1.67)^{* * *}\end{array}$

Recommendation from a health professional to quit smoking

No $\quad 1.00$ (reference) 1.00 (reference)

Yes $\quad 1.15(1.10,1.21)^{* * *} 1.15(1.10,1.21)^{* * *}$

Exposure to anti-smoking campaigns

$\begin{array}{lll}\text { No } & 1.00 \text { (reference) } & 1.00 \text { (reference) } \\ \text { Yes } & 1.04(0.96,1.11) & 1.04(0.96,1.11)\end{array}$

(Continued to the next page)

al-level factors were also significantly associated with attempting to quit; these included sex, age, education level, marital status, oc- 
Table 3. Continued

\begin{tabular}{|c|c|c|}
\hline \multirow{2}{*}{ Variables } & \multicolumn{2}{|c|}{ Smokers' quit attempts } \\
\hline & Model 2 & Model 3 \\
\hline \multicolumn{3}{|l|}{ Community- level } \\
\hline \multicolumn{3}{|c|}{ Financial independence rate $(\%)^{1}$} \\
\hline 1st quartile ( $\leq 19.6)$ & - & 1.00 (reference) \\
\hline 2nd quartile ( $\leq 25.8)$ & - & $1.10(0.98,1.25)$ \\
\hline 3rd quartile ( $\leq 41.5)$ & - & $1.02(0.90,1.16)$ \\
\hline 4th quartile (>41.5) & - & $1.11(0.96,1.28)$ \\
\hline \multicolumn{3}{|l|}{ Community classification } \\
\hline Rural & - & 1.00 (reference) \\
\hline City & - & $1.07(0.90,1.26)$ \\
\hline Metropolis & - & $1.08(0.83,1.29)$ \\
\hline \multicolumn{3}{|l|}{ Area size $\left(\mathrm{km}^{2}\right)^{1}$} \\
\hline 1st quartile ( $\leq 47.2)$ & - & 1.00 (reference) \\
\hline 2nd quartile ( $\leq 378.3$ ) & - & $1.13(0.99,1.28)$ \\
\hline 3rd quartile ( $\leq 631.9)$ & - & $1.10(0.91,1.29)$ \\
\hline 4th quartile (>631.9) & - & $1.08(0.89,1.30)$ \\
\hline \multicolumn{3}{|c|}{ Tobacco outlet density (per 1,000 persons) ${ }^{1}$} \\
\hline 1st quartile $(\leq 2.7)$ & - & 1.00 (reference) \\
\hline 2nd quartile $(\leq 3.5)$ & - & $0.93(0.80,1.07)$ \\
\hline 3rd quartile $(\leq 4.7)$ & - & $0.95(0.83,1.11)$ \\
\hline 4th quartile (>4.7) & - & $0.82(0.70,0.98)^{*}$ \\
\hline \multicolumn{3}{|l|}{ Random effect } \\
\hline \multicolumn{2}{|c|}{ Variance of community (SD) $0.104(0.013)$} & $0.100(0.012)$ \\
\hline ICC & 0.031 & 0.030 \\
\hline
\end{tabular}

Model 2, adjusted for individual level variables; Model 3, adjusted for individual and community level variables.

$\mathrm{OR}$, odds ratio; $\mathrm{Cl}$, confidence interval; KRW, Korean won; SD, standard deviation; ICC, intraclass correlation coefficient

'For all variables measured using quartiles, the first quartile is the lowest and the fourth quartile is the highest.

${ }^{*} p<0.05,{ }^{* *} p<0.01,{ }^{* * *} p<0.001$.

cupation, smoking frequency, average smoking volume per day, previous experience with smoking cessation education, and a health professional's recommendation to quit smoking. Of the community-level variables, the financial independence rate, community classification, and area size did not have a significant effect, whereas tobacco outlet density did. Participants who resided in communities in the fourth quartile of tobacco outlet density (i.e., with the highest density) had an OR of 0.82 for attempting to quit, compared to those living in regions in the first quartile of tobacco outlet density (i.e., lowest density).

ICCs were calculated to assess the random effects of each model. The ICC of the basic model (model 1) was 0.037 . The community-level variables contributed to $3.7 \%$ of the quit attempt distribution. Models 2 and 3 had ICCs of 0.031 and 0.030 , respectively. The community-level variables had significant effects on quit attempts, despite smaller contributions to the overall distribution.

\section{DISCUSSION}

Multi-level analyses were carried out to identify individual-level and community-level factors affecting adult smokers' quit attempts. The results showed that individual-level factors with significance include sex, age, education level, marital status, occupation, smoking frequency, daily average smoking amount, previous experience with smoking cessation education, and a health professional's recommendation to quit smoking. In terms of community-level factors, the density of tobacco retailers in the community had significance, even after controlling for individual-level factors.

Such results were similar to those of previous studies that quit smoking rate is lower in females than in males [18] and that strategies to promote the intention to quit smoking are required as $47.8 \%$ of female smokers have no intention to quit [19]. The results are also consistent with the outcome of Ahn [20]'s research that the likelihood of quit attempts decreased with age. Other than the physical difference between males and females, this tendency seems to come from the fact that female smokers do not receive proper smoking cessation education or advice because they are not able to openly express their smoking problems or intention to quit smoking due to social norms. The finding regarding age, the outcome seems to reflect smokers' view that quitting their longterm habit of smoking in old age would not practically be effective for health [21]. Smokers with spouses were much more likely to attempt to quit smoking than those without spouses, which coincides with the results of Abdullah et al. [22]. As was found by Ryu et al. [23] and Jeon [24], higher education levels and lower smoking amounts were associated with a higher likelihood of attempting to quit. Moreover, the likelihood of quit attempts was higher in smokers who had experienced smoking cessation education $[20,23]$ and those who had received recommendations to quit smoking from health professionals [25], aligning with previous research.

This study also found that there were fewer attempts to quit among smokers living in communities with high tobacco outlet densities than among smokers living in communities with low tobacco outlet densities. The findings are consistent with the results of research conducted in Scotland, which showed that the likelihood of quitting smoking was lower among smokers living in regions where tobacco retailers are highly concentrated [13]. This is also consistent with previous reports that smokers in such regions had low self-efficacy related to smoking and were unlikely to consider quitting smoking [8].

Tobacco outlets may affect smokers and smoking behaviours in several ways. Visible tobacco products and advertising increase the likelihood of smoking initiation, enhance brand awareness, and facilitate unplanned purchases. Tobacco outlets both provide routes through which smokers can purchase tobacco and expose smokers to tobacco advertisements and promotions. A higher regional tobacco outlet density reduces the cost and effort for smokers to purchase tobacco; these changes lead to increased tobacco purchasing behaviour $[5,11]$ and reduced smoking cessation in- 
tent. Furthermore, because tobacco outlets directly expose consumers to advertisements and promotions, smokers are more frequently exposed to tobacco advertisements and sales promotions when there are more tobacco outlets in the region. Previous studies have shown that smokers exposed to tobacco advertisements and sales promotions exhibit an increased desire to smoke [26] and an increased likelihood to purchase tobacco impulsively [27], both of which hinder their ability to quit smoking.

Given the effects of tobacco outlets on smokers and community members, these outlets should be considered in tobacco control policies. Particularly in Korea, unlike other countries, retailers selling other goods or services such as convenience stores, supermarkets, lottery shops, stationery stores, and hardware stores sell and advertise tobacco as well. This is the reason for the existence of so many tobacco retailers in our daily lives, which also leads to a higher retailer-to-population ratio in cities and rural areas than in metropolises. Thus, policies to control tobacco retailers are necessary to close the gap in health disparities due to smoking. Currently, Korea has lenient licensing criteria for tobacco outlets and minimal restrictions regarding the number of tobacco retailers within specific regions. In addition, there are insufficient regulations on tobacco advertisements and promotions within tobacco outlets.

There are several challenges involved in the implementation of effective tobacco control policy. Since tobacco retailers are licensed and managed by local governments under the Tobacco Business Act, the development and implementation of integrative management of tobacco retailers at the regional level may prove challenging. In addition, it is difficult to make generalizations regarding the tobacco retailer distribution process among regions. Furthermore, the law does not restrict the number of tobacco retailers within a region-it only stipulates that outlets must be at least 50 meters apart from each other; therefore, new retailers continue to emerge. In Korea, tobacco advertisements can be legally displayed inside outlets, allowing tobacco companies to post a variety of enticing advertisements inside these outlets.

Some countries have implemented policies to restrict the locations and numbers of tobacco retail stores. There is also a policy to restrict tobacco sales and advertising stores through local community initiatives, and discussions are being held to monitor compliance and strengthen public awareness [28].

This study has some limitations that should be addressed. First, since the research data did not include individual smokers' home addresses, tobacco outlet density had to be defined as the number of tobacco retailers per population. More accurate results could have been obtained if areas or routes frequently used by respondents could have been investigated based on information about individual smokers' addresses. Second, only a few community level factors were considered. Few previous studies have investigated community-level factors affecting smoking cessation, and a broader range of factors should be considered. Third, this study has the inherent limitation of all cross-sectional studies: since the research data were obtained only at a specific point in time, and not over time, they do not provide information regarding changes in the variables or causal relationships between the variables. In addition, further studies should be conducted considering the possibility that the tobacco industry may have established more tobacco retailers in the areas where the smoking population and tobacco consumption are high to promote tobacco marketing.

Despite these limitations, this study is meaningful in that it used nationwide data about individual and community status, surveyed at the community-level, to investigate the overall distribution of tobacco retailers across the country, the characteristics of current smokers, and the factors related to individual and community status that affect quit attempts by smokers. Furthermore, based on the knowledge that a higher density of tobacco outlets reduces the possibility of quitting smoking, it was confirmed that the tobacco outlet density in the community affects the likelihood of attempting to quit among smokers. This means that a communitylevel strategy for tobacco outlet control is needed to cope with this risk factor for community health.

This study identified a need for emphasizing tobacco supply reduction measures. Efforts to reduce tobacco use may include restrictions on the locations and numbers of tobacco outlets, while considering regional characteristics. Furthermore, regulations on tobacco marketing (e.g., tobacco displays, advertisements, and promotions) within tobacco outlets should be considered to create environments conducive to smoking cessation.

\section{CONFLICT OF INTEREST}

The authors have no conflicts of interest to declare for this study.

\section{FUNDING}

None.

\section{ACKNOWLEDGEMENTS}

None.

\section{AUTHOR CONTRIBUTIONS}

Conceptualization: SIC. Data curation: JK. Formal analysis: JK. Funding acquisition: None. Methodology: SIC, JK. Project administration: SIC. Visualization: JK. Writing - original draft: JK, SIC. Writing - review \& editing: SIC, JK.

\section{ORCID}

Jaehyung Kong: https://orcid.org/0000-0002-1572-2984; Sung-il Cho: https://orcid.org/0000-0003-4085-1494.

\section{REFERENCES}

1. GBD 2016 Risk Factors Collaborators. Global, regional, and national comparative risk assessment of 84 behavioural, environ- 
mental and occupational, and metabolic risks or clusters of risks, 1990-2016: a systematic analysis for the Global Burden of Disease Study 2016. Lancet 2017;390:1345-1422.

2. Korea Disease Control and Prevention Agency. 2017 Korea National Health and Nutrition Examination Survey (KNHANES); 2019 [cited $2021 \mathrm{Feb} 24$ ]. Available from: https://knhanes.kdca. go.kr/knhanes/sub04/sub04_04_01.do (Korean).

3. National Health Insurance Service. Evaluation of socioeconomic effects and regulatory policies on major health risk factors. Wonju: Sam-Young; 2015, p. 38 (Korean).

4. Robert SA. Community-level socioeconomic status effects on adult health. J Health Soc Behav 1998;39:18-37.

5. Paul CL, Mee KJ, Judd TM, Walsh RA, Tang A, Penman A, et al. Anywhere, anytime: retail access to tobacco in New South Wales and its potential impact on consumption and quitting. Soc Sci Med 2010;71:799-806.

6. Hausman J, Leibtag E. Consumer benefits from increased competition in shopping outlets: measuring the effect of Wal-Mart. J Appl Econ (Chichester Engl) 2007;22:1157-1177.

7. Cantrell J, Anesetti-Rothermel A, Pearson JL, Xiao H, Vallone D, Kirchner TR. The impact of the tobacco retail outlet environment on adult cessation and differences by neighborhood poverty. Addiction 2015;110:152-161.

8. Young-Wolff KC, Henriksen L, Delucchi K, Prochaska JJ. Tobacco retailer proximity and density and nicotine dependence among smokers with serious mental illness. Am J Public Health 2014;104: 1454-1463.

9. Chaiton MO, Mecredy G, Cohen J. Tobacco retail availability and risk of relapse among smokers who make a quit attempt: a population-based cohort study. Tob Control 2018;27:163-169.

10. Kirchner TR, Anesetti-Rothermel A, Bennett M, Gao H, Carlos $\mathrm{H}$, Scheuermann TS, et al. Tobacco outlet density and converted versus native non-daily cigarette use in a national US sample. Tob Control 2017;26:85-91.

11. Reitzel LR, Cromley EK, Li Y, Cao Y, Dela Mater R, Mazas CA, et al. The effect of tobacco outlet density and proximity on smoking cessation. Am J Public Health 2011;101:315-320.

12. Halonen JI, Kivimäki M, Kouvonen A, Pentti J, Kawachi I, Subramanian SV, et al. Proximity to a tobacco store and smoking cessation: a cohort study. Tob Control 2014;23:146-151.

13. Pearce J, Rind E, Shortt N, Tisch C, Mitchell R. Tobacco retail environments and social inequalities in individual-level smoking and cessation among Scottish adults. Nicotine Tob Res 2016;18: 138-146.

14. Pulakka A, Halonen JI, Kawachi I, Pentti J, Stenholm S, Jokela M, et al. Association between distance from home to tobacco outlet and smoking cessation and relapse. JAMA Intern Med 2016;176: 1512-1519.
15. Lipperman-Kreda S, Mair C, Grube JW, Friend KB, Jackson P, Watson D. Density and proximity of tobacco outlets to homes and schools: relations with youth cigarette smoking. Prev Sci 2014;15: 738-744.

16. Chaiton M, Mecredy G, Rehm J, Samokhvalov AV. Tobacco retail availability and smoking behaviours among patients seeking treatment at a nicotine dependence treatment clinic. Tob Induc Dis 2014;12:19.

17. Kang YW, Ko YS, Kim YJ, Sung KM, Kim HJ, Choi HY, et al. Korea Community Health Survey data profiles. Osong Public Health Res Perspect 2015;6:211-217.

18. Perkins KA, Scott J. Sex differences in long-term smoking cessation rates due to nicotine patch. Nicotine Tob Res 2008;10:12451250.

19. Park KY. Predictors of intention to quit smoking among woman smokers in Korea. J Korean Acad Fundam Nurs 2014;21:253-263 (Korean).

20. Ahn HR. Factors associated with intention to quit smoking in community-dwelling male adult smokers. J Korean Acad Community Health Nurs 2015;26:364-371 (Korean).

21. Cataldo JK. Clinical implications of smoking and aging: breaking through the barriers. J Gerontol Nurs 2007;33:32-41.

22. Abdullah AS, Ho LM, Kwan YH, Cheung WL, McGhee SM, Chan WH. Promoting smoking cessation among the elderly: what are the predictors of intention to quit and successful quitting? J Aging Health 2006;18:552-564.

23. Ryu SY, Shin JH, Kang MG, Park J. Factors associated with intention to quit smoking among male smokers in 13 communities in Honam region of Korea: 2010 Community Health Survey. Korean J Health Educ Promt 2011;28:75-85 (Korean).

24. Jeon HJ. The study of smoker's no-smoking decision and success factors-the implications of no-smoking policy. Korean Soc Secur Stud 2013;29:89-103 (Korean).

25. Schroeder SA. What to do with a patient who smokes. JAMA 2005; 294:482-487.

26. Kim AE, Nonnemaker JM, Loomis BR, Shafer PR, Shaikh A, Hill $\mathrm{E}$, et al. Influence of point-of-sale tobacco displays and graphic health warning signs on adults: evidence from a virtual store experimental study. Am J Public Health 2014;104:888-895.

27. Li L, Borland R, Fong GT, Thrasher JF, Hammond D, Cummings KM. Impact of point-of-sale tobacco display bans: findings from the International Tobacco Control Four Country Survey. Health Educ Res 2013;28:898-910.

28. Wahyuti W, Hasairin S, Mamoribo S, Ahsan A, Kusuma D. Monitoring compliance and examining challenges of a smoke-free policy in Jayapura, Indonesia. J Prev Med Public Health 2019;52: 427-432. 